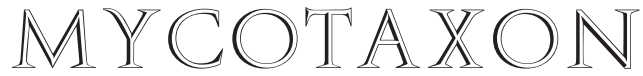

Volume 118, pp. 17-26

http://dx.doi.org/10.5248/118.17

October-December 2011

\title{
Discrimination of Gigaspora species by PCR specific primers and phylogenetic analysis
}

\section{Gladstone Alves da Silva $^{1^{*}}$, Erica Lumini², Valeria Bianciotto ${ }^{2}$, PaOla Bonfante ${ }^{2} \&$ LeOnor Costa Maia ${ }^{1}$}

${ }^{1}$ Departamento de Micologia, CCB, Universidade Federal de Pernambuco, Av. Prof. Nelson Chaves, s/n. 50670-420 Recife, PE, Brasil

${ }^{2}$ Dipartimento di Biologia Vegetale dell' Università and Istituto per la Protezione delle Piante, (Sezione di Torino) del CNR - Viale P.A. Mattioli 25, 10125 Torino, Italy

*CORRESPONDENCE TO: gladstonesilva@yahoo.com

Aвstract - Species of arbuscular mycorrhizal fungi (AMF) are usually identified by the morphological characteristics of their spores. However, considering the difficulties in diagnosing their taxa, the construction of species-specific primers has been proposed as an identification alternative. In this paper the problem of distinguishing different Gigaspora species with slight morphological differences was solved using species-specific primers and SSU and LSU rDNA sequence analyses of $18 \mathrm{AM}$ fungal isolates comprising seven species. Neighbor joining, maximum parsimony, and maximum likelihood analyses were performed to evaluate the phylogenetic affiliation of the isolates, and a new reverse PCR primer (ALB1) specific for Gigaspora albida was designed and tested with 11 Gigaspora isolates (four species). The results confirmed misidentification of 'G. albida' FL 927 and 'G. margarita' BR 444 and supported referring FL 927 to G. rosea and BR 444 to G. albida.

KEY wORDs - phylogeny, ribosomal sequences, Glomeromycota

\section{Introduction}

There are approximately 220 species of arbuscular mycorrhizal fungi (AMF) (Stockinger et al. 2010). Morphological differences in spore structure are usually used to distinguish between individual species, but this requires a great deal of experience (Morton 1993, Bentivenga \& Morton 1994). More practical methods are needed, so that AMF can be identified directly not only in the rhizosphere, but also after host root colonization. DNA analytical methods involving electrophoretic profiles (Wyss \& Bonfante 1993), sequence comparisons (Daniell et al. 2001, Husband et al. 2002, Mummey \& Rillig 2007, Stukenbrock \& Rosendahl 2005), PCR-DGGE (Souza et al. 2004), species- 
specific primers (Gamper \& Leuchtmann 2007, Geue \& Hock 2004, Lanfranco et al. 1995, 1999, 2001, Millner et al. 1998, 2001a, 2001b, Redecker 2000), and DNA barcodes (Stockinger et al. 2010) are being developed that would allow identification of individual AMF species in an ecological context. For example, species-specific PCR primers could be used to discriminate morphologically similar species or even to identify species within colonized roots. However, to date only a small number of species-specific probes has been developed.

After Oehl et al. (2008) divided the Gigasporaceae into four families and six genera, Morton \& Msiska (2010) proposed dividing Gigasporaceae into just three genera -Gigaspora, Racocetra, Scutellospora. Gigaspora has five species (Bentivenga \& Morton 1995) in which the morphological variation is low (Bago et al. 1998, Souza et al. 2004, Lanfranco et al. 2001), and only diameter, color and spore wall thickness of glomerospores have been used for species identification (Bentivenga \& Morton 1995). Species-specific primers designed for G. margarita (Lanfranco et al. 1999) and G. rosea (Lanfranco et al. 2001) have shown to be effective in solving such morphological conflicts. In this study we show how a species-specific PCR primer constructed for G. albida helps solve problems associated with discriminating Gigaspora species and evaluate Gigaspora phylogenetically through SSU and LSU rDNA analyses.

\section{Materials \& methods}

\section{AM fungi}

Eleven reference isolates (TABLE 1) representing Gigaspora propagated in pot cultures were selected.

\section{Intracellular bacteria}

Presence of intracellular bacteria was assessed with the Live/Dead Bac-Light bacterial viability kit (Molecular Probes, Inc., Eugene, OR, USA) following Bianciotto et al. (1996).

\section{DNA extraction}

Ten to 50 spores were washed in distilled water, sonicated 3-4 times, crushed in 50-100 $\mu$ l of 1x REDTaq PCR Reaction Buffer (10 mM Tris-HCl pH 8.3, $50 \mathrm{mM} \mathrm{KCl,} 1.1$ $\mathrm{mM} \mathrm{MgCl}$ and $0.01 \%$ gelatin) (Sigma-Aldrich, Milan, Italy), and centrifuged at 1000 $\mathrm{RPM}$ for $2 \mathrm{~min}$. The supernatant containing the DNA was incubated at $95^{\circ} \mathrm{C}$ for $13 \mathrm{~min}$. After extraction, the DNA was stored at $-20^{\circ} \mathrm{C}$.

\section{Design of PCR primers, amplification and sequencing}

A new species-specific reverse PCR primer ALB1 (5'-CCCAACTAAAAATACTTCAGTC3') was designed for G. albida based on the GenBank ITS sequence AJ239118 and combined with GiITS1 (Lanfranco et al. 1999) to create a 385 bp fragment. For G. margarita and G. rosea, combinations of primers GiITS1+GiITS2 (Lanfranco et al. 1999) and GiITS1-GiR3 (Lanfranco et al. 2001) were used, respectively. 
TABLE 1. Glomeromycota isolates used in PCR amplification tests with species-specific primers and phylogenetic analysis.

\begin{tabular}{llll}
\hline SPECIES $^{\mathrm{a}}$ & IsOLATE & ORIGIN & SOURCE $^{\mathrm{b}}$ \\
\hline Gigaspora albida N.C. Schenck \& G.S. Sm. & BR 601 & Brazil & INVAM \\
G. albida & FL 927 & USA & UFPE \\
G.decipiens I.R. Hall \& L.K. Abbott & BEG 45 & Australia & BEG \\
G. gigantea (T.H. Nicolson \& Gerd.) Gerd. \& Trappe & MN 414D & USA & INVAM \\
G. gigantea & NC 150 & USA & INVAM \\
G. gigantea & WV 932 & USA & INVAM \\
G. gigantea & NC 199A & USA & INVAM \\
G. margarita W.N. Becker \& I.R. Hall & MAFF 52 & Japan & MAFF \\
G. margarita & MAFF 54 & Japan & MAFF \\
G. margarita & BEG 34 & New Zealand & BEG/UNITO \\
G. margarita & BR 444 & Brazil & INVAM \\
G. rosea T.H. Nicolson \& N.C. Schenck & UT 102 & USA & INVAM \\
G. rosea & MAFF 62 & Japan & MAFF \\
G. rosea & BR 151 A & Brazil & INVAM \\
G. rosea & DAOM 194757 & NA & NA \\
Scutellospora calospora (T.H. Nicolson \& Gerd.) & BEG 32 & UK & BEG \\
C. Walker \& F.E. Sanders & & & \\
S. calospora & HDAM-3 & na & na \\
Scutellospora sp. & W 3485 & UK & C. Walker \\
\hline
\end{tabular}

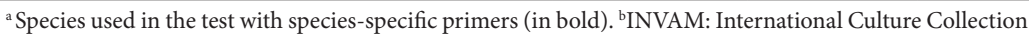
of Arbuscular and Vesicular-Arbuscular Mycorrhizal Fungi, USA; UFPE: Universidade Federal de Pernambuco, Departamento de Micologia, Brasil; MAFF: Ministry of Agriculture, Forest and Fisheries, Japan; BEG European Bank of Glomales, France; UNITO: Università di Torino, Dipartimento di Biologia Vegetale, Italy; na: information not available.

The 28G1 and 28G2 primers (Silva et al. 2006) were used to amplify the partial LSU rDNA region. NS1, NS2, NS3, NS4, NS5 and NS8 were used to obtain the SSU rDNA amplicons (White et al. 1990).

PCR reactions were carried out in a volume of $50 \mu \mathrm{l}$, containing $10 \mathrm{mM}$ Tris- $\mathrm{HCl}$ $\mathrm{pH} 8.3,50 \mathrm{mM} \mathrm{KCl}, 1.1 \mathrm{mM} \mathrm{MgCl}, 0.01 \%$ gelatin, $200 \mu \mathrm{M}$ each dNTPs, $1 \mu \mathrm{M}$ of each primer and 2 units of REDTaq ${ }^{\mathrm{TM}}$ DNA polymerase (SIGMA) (Sigma-Aldrich, Milan, Italy). Cycling parameters were $45 \mathrm{~s}$ at $94^{\circ} \mathrm{C}, 1 \mathrm{~min}$ at $55^{\circ} \mathrm{C}, 1 \mathrm{~min}$ at $72^{\circ} \mathrm{C}$ for $40 \mathrm{cycles}$, with a final elongation of $7 \mathrm{~min}$ at $72^{\circ} \mathrm{C}$ followed the last cycle. The amplicons were visualized on $1.5 \%$ agarose gel with ethidium bromide. The amplified products for SSU and LSU rDNA were purified with a QIAquick kit (Qiagen S.p.A., Milan, Italy) following the manufacturer's instruction and sequenced (accession numbers are listed in TABLE 1). Sequencing was made by GeneLab (Roma, Italy).

\section{Sequence alignment and phylogenetic analysis}

Prior to phylogenetic analysis, a BLASTn query of the National Center for Biotechnology information databases demonstrated that sequences obtained from AMF species were affiliated with the genus Gigaspora. 
Sequences of 15 Gigaspora and 11 Scutellospora isolates (some obtained from GenBank) were selected to align SSU and LSU rDNA (TABLE 1) using Clustal X (Larkin et al. 2007) and edited with BioEdit (Hall 1999).

For phylogenetic analyses and tree construction, neighbor joining (NJ), maximum parsimony (MP), and maximum likelihood (ML) analysis with 1,000 bootstrap replications were performed using PAUP4 (Phylogenetic Analysis Using Parsimony vers. 4, Swofford 2003). NJ and ML analyses were performed using parameters obtained from ModelTest 3.7 (Posada \& Crandall 1998). Scutellospora calospora and Scutellospora sp. were used as outgroup.

\section{Results}

\section{Morphological observations of isolates FL 927 and BR 444}

Isolates FL 927 ('G. albida') and BR 444 ('G. margarita’) had morphological characters similar to other Gigaspora species: spore wall thickness [9.6-(12.2)$14.4 \mu \mathrm{m}$ and 12-(13.9)-16.8 $\mu \mathrm{m}$, respectively] and spore diameter [230-(282)$360 \mu \mathrm{m}$ and 250-(320)-384 $\mu \mathrm{m}$, respectively]. However, the 'G. margarita' BR 444 spores were hyaline/white to yellow and lacked the characteristic green (G. albida) or pink (G. rosea) coloration observed in reference isolates G. albida BR 601 and G. rosea UT 102. All isolates of 'G. margarita' BR 444 and G. albida BR 601 contained endobacteria, which were absent in all isolates of $G$. rosea and 'G. albida' FL 927.

\section{Testing species-specific primers for taxa of Gigaspora}

Eleven Gigaspora isolates were screened for PCR amplification of a short partial nuclear ITS rDNA fragment (385bp) with species-specific primers (TABLE 1). The primers GiITS1+GiITS2 amplified only the G. margarita species, excluding isolate 'G. margarita' BR 444, which did not amplify at all (FIG. 1A). The combination of the species-specific primer constructed for G. rosea (GiR3) with GiITS1 amplified not only the isolates of G. rosea, but also 'G. albida' FL 927 and showed a slight reaction to the DNA from spores of G. albida BR 601 and 'G. margarita' BR 444 (FIG. 1B), while the GiITS1+ALB1 primer pair amplified only G. albida BR 601 and 'G. margarita' BR 444 (FIG. 1C). These results support a misidentification for 'G. albida' FL 927 and 'G. margarita' BR 444.

\section{Phylogenetic analysis of Gigaspora from SSU and LSU rDNA}

In the SSU rDNA phylogenetic analyses (NJ, MP and $\mathrm{ML}$ ), the genus Gigaspora was supported as a monophyletic group with 100\% of the bootstrap value (FIG. 2). Three subclades were observed in the genus, the first grouping 'G. margarita' BR 444 with all isolates of G. albida and G. rosea. In the second cluster just G. gigantea was present and in the last group all isolates of G. margarita (except 'G. margarita' BR 444) appeared together with G. decipiens.

In the tree constructed with the LSU rDNA, Gigaspora was monophyletic with high bootstrap support (FIG. 3). All isolates of G. margarita (except 


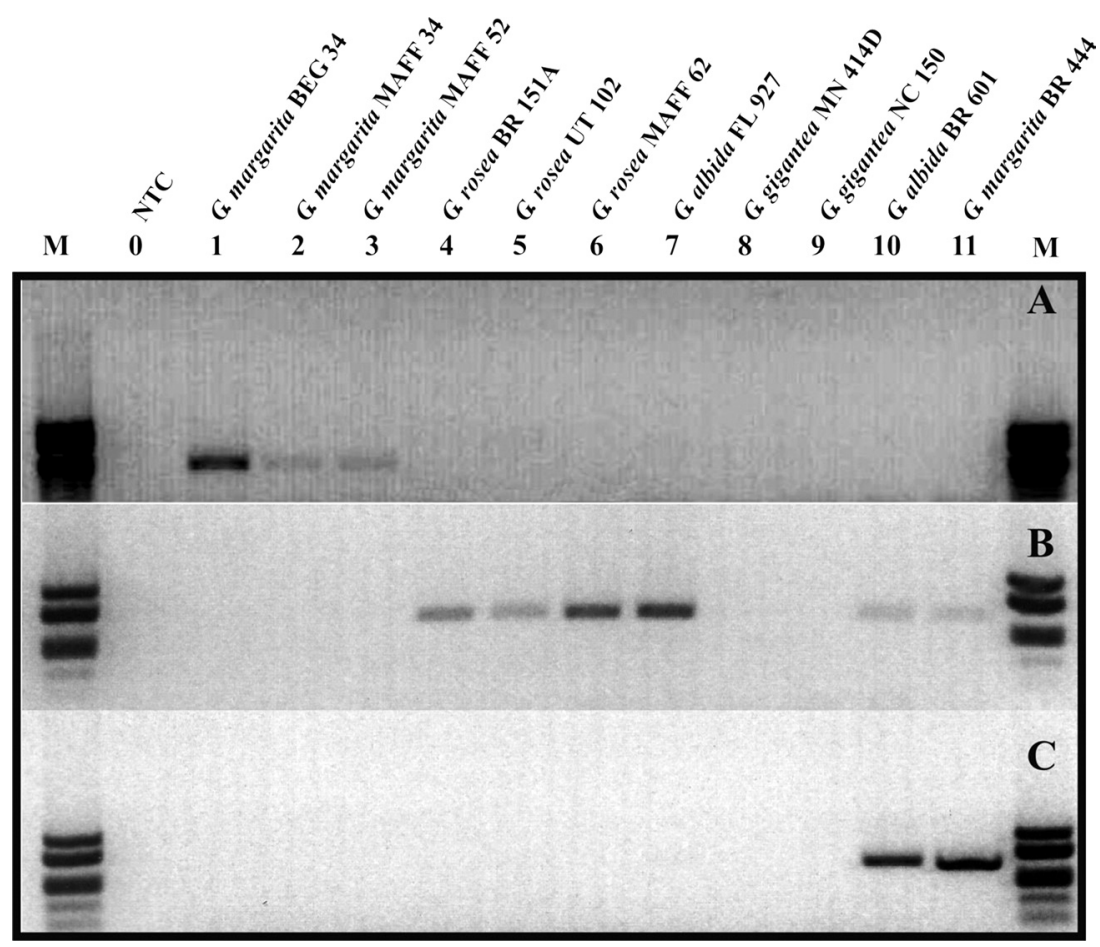

FIg. 1. Agarose gels (1.5\%) with PCR products of the Gigaspora spp. Different combinations of primers were used: A) GiITS1-GiITS2; B) GiITS1-GiR3; C) GiITS1-ALB1. M = pUC 18 digested with Hae III. NTC = no template control.

'G. margarita' BR 444) clustered together. Two isolates of Gigaspora gigantea grouped in the same clade, Gigaspora albida BR 601 and 'Gigaspora margarita' BR 444 clustered together and Gigaspora rosea UT 102 was close to 'Gigaspora albida' FL 927. Based on SSU and LSU rDNA analyses 'Gigaspora margarita' BR 444 has been misidentified.

\section{Discussion}

Due to the low morphological variation amongst Gigaspora species (Bentivenga \& Morton 1995), some papers have reported species misidentification (Bago et al. 1998, Souza et al. 2004, Lanfranco et al. 2001). These studies also report the usefulness of molecular approach as an identification tool. Based on sequences of SSU rDNA and isozyme analysis, Bago et al. (1998) divided Gigaspora into three subgeneric groups: the first with G. margarita and G. decipiens, the second with G. albida and G. rosea, and the third with G. gigantea. In this paper these same groups were observed in the phylogeny generated by 


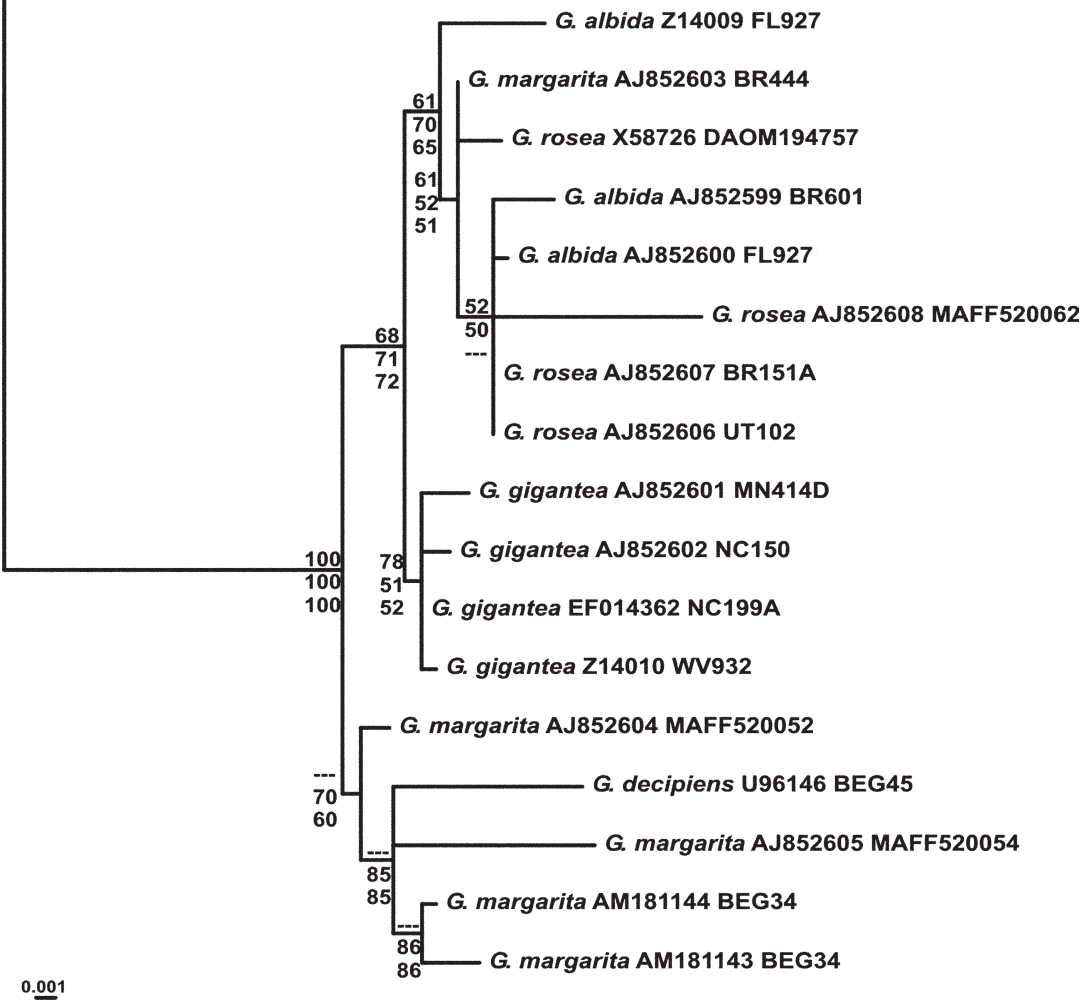

FIG. 2. Phylogenetic reconstruction of the Gigaspora obtained from SSU rDNA sequences ( 1700 bp). The NJ and ML analyses were performed with HKY85 + I substitution model. Bootstrap values (in \%) are from neighbor joining (NJ), maximum parsimony (MP) and maximum likelihood (ML) analyses (1000 bootstraps), respectively. Only topologies with bootstrap values of at least $50 \%$ are shown. (Consistency Index $=0.88$; Retention Index $=0.93$ ).

SSU rDNA, and just ' $G$. margarita' BR 444 was out of the correct clade. In the LSU rDNA tree, the isolate BR 444 also grouped together with G. albida BR 601, whereas the isolate FL 927 (identified as G. albida) was clustered with G. rosea. Bago et al. (1998) observed that the isolates BR 444, identified initially as G. margarita, and FL 927 (described as G. albida), should instead be ascribed to G. albida and G. rosea, respectively. The PCR amplification tests with speciesspecific primers in this study also indicated that these two isolates should be reclassified as G. albida and G. rosea. Nevertheless recently Msiska \& Morton 
S. calospora AJ510231 BEG32

S. calospora EU346867 HDAM-3

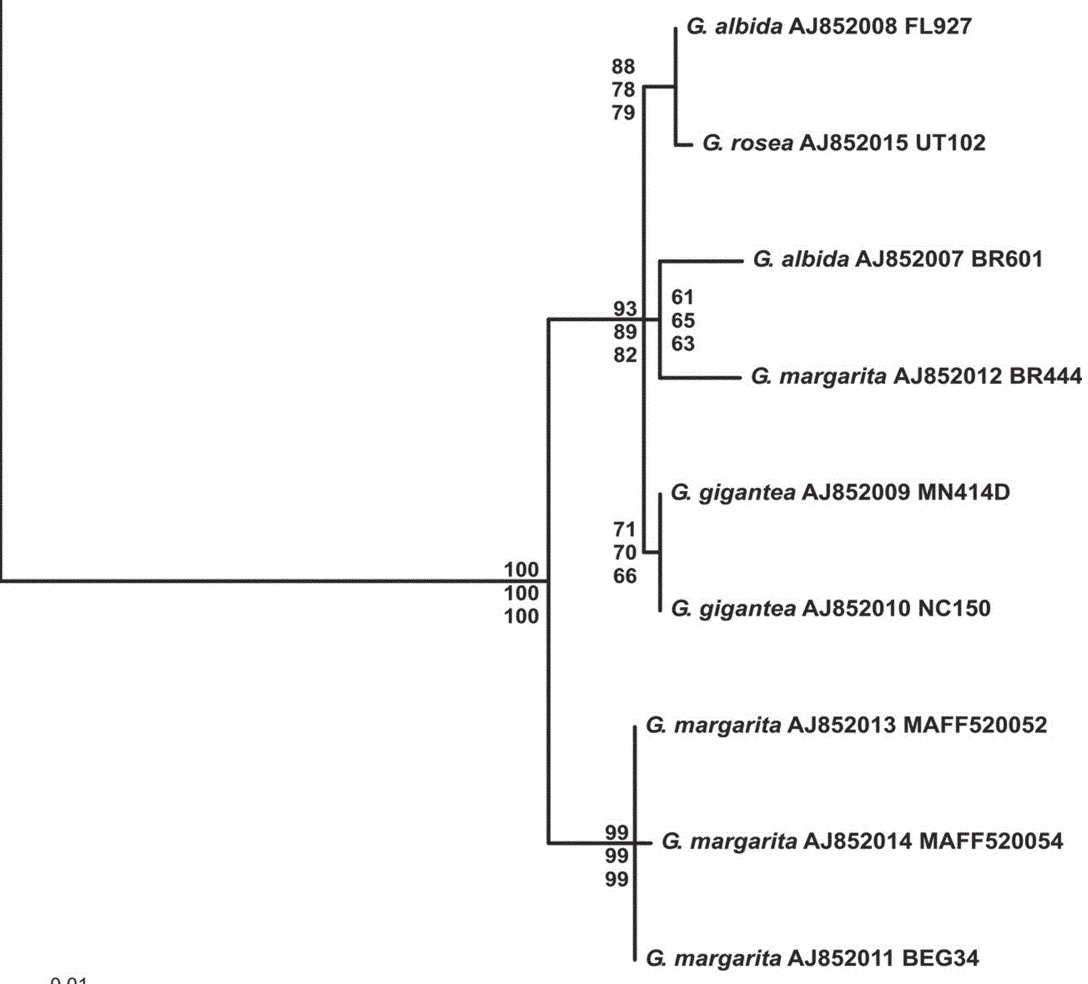

0.01

FIG. 3. Phylogenetic reconstruction of the Gigaspora obtained from LSU rDNA sequences ( 450 bp). The NJ and ML analyses were performed with GTR substitution model. Bootstrap values (in $\%$ ) are from neighbor joining (NJ), maximum parsimony (MP) and maximum likelihood (ML) analyses (1000 bootstraps), respectively. Only topologies with bootstrap values of at least 50\% are shown. (Consistency Index $=0.93$; Retention Index $=0.93$ ).

(2009), based on $\beta$-tubulin gene, reported that 'G. margarita' BR 444 did not group with G. albida or G. rosea, but with G. decipiens.

Using PCR-DGGE analysis, Souza et al. (2004) already observed, as we confirmed here, that the FL 927 isolate, originally identified as G. albida, should be ascribed to G. rosea, indicating identification problems. Endobacteria are usually observed in glomerospores of Gigaspora species, with the exception of 
G. rosea isolates. Bacteria were not found in 'Gigaspora albida' FL 927, further substantiating the need for reclassification.

Van Tuinen et al. (1998) were the first to design specific primers for Gigaspora species (G. rosea) that amplify a region of the LSU rDNA. Because these authors tested cross-amplification only with species of other AMF genera, it is not possible to establish whether the primers amplify other Gigaspora species. Currently there are primers specific for two Gigaspora species (G. margarita and G. rosea); nevertheless, we report that the reverse primer GiR3 (Lanfranco et al. 2001) also amplifies G. albida isolates. As Lanfranco et al. (2001) did not use G. albida and G. decipiens in their analyses with species-specific primers, it was not possible to establish how specific the primers are to G. rosea and G. margarita. Of the five known Gigaspora species (Bentivenga \& Morton 1995), only G. decipiens was not used in this work.

In summary, our results show that different specific PCR primer pairs and phylogenetic studies can help discriminate among Gigaspora species with similar spore morphologies and support the utility of these primers and phylogenetic analysis for solving problems in identifying groups of species in Gigasporaceae with a low morphological variation.

\section{Acknowledgements}

We are grateful to Dr. Fritz Oehl and Dr. Renata Gomes de Souza for the valuable comments on the manuscript. L.C. Maia acknowledges the Conselho Nacional de Desenvolvimento Científico e Tecnológico $(\mathrm{CNPq})$ for a research grant. The authors wish to thank Dr. J. Morton and Dr. M. Saito for providing fungal isolates. We are grateful to Dr. David Bousfield for the critical reading of the manuscript and appreciate the corrections by Shaun Pennycook, Nomenclatural Editor, and suggestions by Lorelei L. Norvell, Editor-in-Chief. This research was funded by the Italian National Council of Research (CNR), Cassa di Risparmio di Torino and Centro di Eccellenza per la Biosensoristica Vegetale e Microbica.

\section{Literature cited}

Bago B, Bentivenga S, Brenac V, Dodd JC, Piché Y, Simon L. 1998. Molecular analysis of Gigaspora (Glomales, Gigasporaceae). New Phytol. 139: 581-588.

http://dx.doi.org/10.1046/j.1469-8137.1998.00212.x

Bentivenga SP, Morton JB. 1994. Systematics of glomalean endomycorrhizal fungi: current views and future directions. In: Pfleger FL, Linderman RG. (eds). Mycorrhizae and Plant Health: 283-308. APS Press, St. Paul.

Bentivenga SP, Morton JB. 1995. A monograph of the genus Gigaspora, incorporating developmental patterns of morphological characters. Mycologia 87: 719-731.

http://dx.doi.org/10.2307/3760818

Bianciotto V, Bandi C, Minerdi D, Sironi M, Tichy HV, Bonfante P. 1996. An obligately endosymbiotic mycorrhizal fungus itself harbors obligately intracellular bacteria. Appl. Environ. Microbiol. 62: 3005-3010. 
Daniell TJ, Husband R, Fitter AH, Young JPW. 2001. Molecular diversity of arbuscular mycorrhizal fungi colonizing arable crops. FEMS Microbiol. Ecol. 36: 203-209.

http://dx.doi.org/10.1111/j.1574-6941.2001.tb00841.x

Gamper H, Leuchtmann A. 2007. Taxon-specific PCR primers to detect two inconspicuous arbuscular mycorrhizal fungi from temperate agricultural grassland. Mycorrhiza 17: 145-152. http://dx.doi.org/10.1007/s00572-006-0092-3

Geue H, Hock B. 2004. Determination of Acaulospora longula and Glomus subgroup Aa in plant roots from grassland using new primers against the large subunit ribosomal DNA. Mycol. Res. 108: 76-83. http://dx.doi.org/10.1017/S0953756203009080

Hall TA. 1999. BioEdit: a user-friendly biological sequence alignment editor and analysis program for Windows 95/98/NT. Nucl. Acids Symp. Ser. 41: 95-98.

Husband R, Herre EA, Young JPW. 2002. Temporal variation in the arbuscular mycorrhizal communities colonizing seedlings in a tropical forest. FEMS Microbiol. Ecol. 42: 131-136. http://dx.doi.org/10.1111/j.1574-6941.2002.tb01002.x

Lanfranco L, Wyss P, Marzachi C Bonfante P. 1995. Generation of RAPD-PCR primers for the identification of isolates of Glomus mosseae, an arbuscular mycorrhizal fungus. Mol. Ecol. 4: 61-68. http://dx.doi.org/10.1111/j.1365-294X.1995.tb00192.x

Lanfranco L, Delpero M, Bonfante P. 1999. Intrasporal variability of ribosomal sequences in the endomycorrhizal fungus Gigaspora margarita. Mol. Ecol. 8: 37-45. http://dx.doi.org/10.1046/j.1365-294X.1999.00535.x

Lanfranco L, Bianciotto V, Lumini E, Souza M, Morton JB, Bonfante P. 2001. A combined morphological and molecular approach to characterize isolates of arbuscular mycorrhizal fungi in Gigaspora (Glomales). New Phytol. 152: 169-179. http://dx.doi.org/10.1046/ $\overline{\text { j.0028-646x.2001.00233.x }}$

Larkin MA, Blackshields G, Brown NP, Chenna R, McGettigan PA, McWilliam H, Valentin F, Wallace IM, Wilm A, Lopez R, Thompson JD, Gibson TJ, Higgins DG. 2007. Clustal W and Clustal X version 2.0. Bioinformatics 23: 2947-2948. http://dx.doi.org/10.1093/bioinformatics/btm404

Millner PD, Mulbry WW, Reynolds SL, Patterson CA. 1998. A taxon-specific oligonucleotide probe for temperate zone soil isolates of Glomus mosseae. Mycorrhiza 8: 19-27.

http://dx.doi.org/10.1007/s005720050206

Millner PD, Mulbry WW, Reynolds SL. 2001a. Taxon-specific oligonucleotide primers for detection of Glomus etunicatum. Mycorrhiza 10: 259-265. http://dx.doi.org/10.1007/s005720000085

Millner PD, Mulbry WW, Reynolds SL. 2001b. Taxon-specific oligonucleotide primers for detection of two ancient endomycorrhizal fungi, Glomus occultum and Glomus brasilianum. FEMS Microbiol. Letts. 196: 165-170. http://dx.doi.org/10.1111/j.1574-6968.2001.tb10559.x

Morton JB. 1993. Problems and solutions for the integration of glomalean taxonomy, systematic biology, and the study of endomycorrhizal phenomena. Mycorrhiza 2: 97-109. http://dx.doi.org/10.1007/BF00203855

Morton JB, Msiska Z. 2010. Phylogenies from genetic and morphological characters do not support a revision of Gigasporaceae (Glomeromycota) into four families and five genera. Mycorrhiza 20: 483-496. http://dx.doi.org/ 10.1007/s00572-010-0303-9

Msiska Z, Morton JB. 2009. Phylogenetic analysis of the Glomeromycota by partial $\beta$-tubulin gene sequences. Mycorrhiza 19: 247-254. http://dx.doi.org/10.1007/s00572-008-0216-Z

Mummey DL, Rillig MC. 2007. Evaluation of LSU rRNA-gene PCR primers for analysis of arbuscular mycorrhizal fungal communities via terminal restriction fragment length polymorphism analysis. J. Microbiol. Methods 70: 200-204. http://dx.doi.org/10.1016/j.mimet.2007.04.002 
Oehl F, de Souza FA, Sieverding E. 2008. Revision of Scutellospora and description of five new genera and three new families in the arbuscular mycorrhiza-forming Glomeromycetes. Mycotaxon 106: 311-360.

Posada D, Crandall KA. 1998. Modeltest: testing the model of DNA substitution. Bioinformatics 14: 817-818. http://dx.doi.org/10.1093/bioinformatics/14.9.817

Redecker D. 2000. Specific PCR primers to identify arbuscular mycorrhizal fungi within colonized roots. Mycorrhiza 10: 73-80. http://dx.doi.org/10.1007/s005720000061

Silva GA da, Lumini E, Maia LC, Bonfante P, Bianciotto V. 2006. Phylogenetic analysis of Glomeromycota by partial LSU rDNA sequences. Mycorrhiza 16: 183-189. http://dx.doi.org/10.1007/s00572-005-0030-9

Souza FA de, Kowalchuk GA, Leeflang P, van Veen JA, Smit E. 2004. PCR-denaturing Gradient gel electrophoresis profiling of inter- and intraspecies $18 \mathrm{~S}$ rRNA gene sequence heterogeneity is an accurate and sensitive method to assess species diversity of arbuscular mycorrhizal fungi of the genus Gigaspora. Appl. Environ. Microbiol. 70: 1413-1424. http://dx.doi.org/10.1128/AEM.70.3.1413-1424.2004

Stockinger H, Krüger M, Schüßler A. 2010. DNA barcoding of arbuscular mycorrhizal fungi. New Phytol. 187: 461-474. http://dx.doi.org/10.1111/j.1469-8137.2010.03262.x

Stukenbrock EH, Rosendahl S. 2005. Distribution of dominant arbuscular mycorrhizal fungi among five plant species in undisturbed vegetation of a coastal grassland. Mycorrhiza 15: 497-503. http://dx.doi.org/10.1007/s00572-005-0357-2

Swofford DL. 2003. PAUP*. Phylogenetic Analysis Using Parsimony ${ }^{\star}$ (and Other Methods), Version 4. Sinauer Associates, Sunderland.

van Tuinen D, Jacquot E, Zhao B, Gollotte A, Gianinazzi-Pearson V. 1998. Characterization of root colonization profiles by a microcosm community of arbuscular mycorrhizal fungi using $25 \mathrm{~S}$ rDNA-targeted nested PCR. Mol. Ecol. 7: 879-887. http://dx.doi.org/10.1046/j.1365-294x.1998.00410.x

White TJ, Bruns T, Lee S, Taylor J. 1990. Amplification and direct sequencing of fungal ribosomal RNA genes for phylogenetics. 315-322, in: MA Innis et al. (eds.). PCR protocols: a guide to methods and applications. Academic Press, San Diego.

Wyss P, Bonfante P. 1993. Amplification of genomic DNA of arbuscular-mycorrhizal (AM) fungi by PCR using short arbitrary primers. Mycol. Res. 97: 1351-1357.

http://dx.doi.org/10.1016/S0953-7562(09)80169-X 